\title{
Effectiveness of Homeopathic Treatment for Abnormal Uterine Bleeding: A Double-Blind Randomized Clinical Trial
}

\author{
Zohreh Naderi ${ }^{1}$, Zarin Dadkhah'², Ali Karimi ${ }^{3}$, Razieh Hashemi ${ }^{2,4}$, Maryam Aghaee ${ }^{2}$, Abbas Tavallaii ${ }^{5}$, \\ Mohsen Saberi Isfeedvajani ${ }^{6^{*}}$ \\ ${ }^{1}$ Faculty of Medicine, Baqiyatallah University of Medical Sciences, Tehran, Iran \\ ${ }^{2}$ Department of Obstetrics and Gynecology, Baqiyatallah Hospital, Baqiyatallah University of Medical Sciences, \\ Tehran, Iran \\ ${ }^{3}$ Faculty of Medicine, Tehran University of Medical Sciences, Tehran, Iran \\ ${ }^{4}$ Trauma Research Center, Baqiyatallah University of Medical Sciences, Tehran, Iran \\ ${ }^{5}$ Behavioral Sciences Research Center, Baqiyatallah University of Medical Sciences, Tehran, Iran \\ ${ }^{6}$ Medicine, Quran and Hadith Research Center and Department of Community Medicine, Faculty of Medicine, \\ Baqiyatallah University of Medical Sciences, Tehran, Iran
}

Corresponding Author: Mohsen Saberi Isfeedvajani, MD, Associate Professor, Medicine, Quran and Hadith Research Center and Department of Community Medicine, Faculty of Medicine, Baqiyatallah University of Medical Sciences, Tehran, Iran. Tel: +98-21-81263617, Email: drsaberihaji@gmail.com

Received May 8, 2020; Accepted September 3, 2020; Online Published September 22, 2020

\begin{abstract}
Background: Abnormal uterine bleeding (AUB) is a major health problem for many women. Homeopathy is one of the treatments for this disease.

Objectives: This study was performed to evaluate the efficacy of homeopathic Ipecacuanha (Ipecac) in the treatment of bleeding, pain, and in the quality of life in patients with AUB compared to the control group.

Methods: This double blind randomized clinical trial study was performed on women aged 35-55 years with AUB in Tehran, Iran during the years 2017-2018. In this study, patients were assigned to first group: 25 patients with routine treatment (mefenamic acid capsule) + homeopathic "Ipecac" and second group: 25 patients with mefenamic acid + placebo. Pictorial Blood Loss Assessment Chart (PBAC) score, Visual Analogue Scale (VAS) questionnaire, and General Health Questionnaire (GHQ) were utilized to assess bleeding, pain, and quality of life, respectively.

Results: This study was performed on 50 women with AUB. In this study, the two groups were similar in demographic characteristics. The results showed that despite the relative improvement in PBAC score, duration of bleeding, and depression score in the homeopathic treatment group, this decrease was not statistically significant. The homeopathic treatment group compared to the control group showed more improvement in pain score, physical symptoms, anxiety and insomnia, social dysfunction, and mental health.

Conclusion: Considering the efficacy of homeopathic "Ipecac" in reducing pain and increasing the quality of life of women with AUB in this study, it can be suggested in AUB without the complication of this treatment.

Keywords: Metrorrhagia, Homeopathy, Clinical Trial, Major Depressive Disorder, Quality of Life, Menstruation
\end{abstract}

\section{Background}

Abnormal uterine bleeding (AUB) in women, defined as the change in the size, pattern, or duration of menstrual bleeding in women ${ }^{1}$ is the most common cause of referring women to the physician, ${ }^{2}$ with different reasons and treatments being mentioned in the medical literature.

This disease has a great burden of social and personal issues and has a major impact on the quality of life, productivity, access to health care services and imposes personal costs on the country's health system. ${ }^{3-5}$ AUB is highly prevalent and one-third of all women experience abnormal menstrual bleeding during their lifetime. ${ }^{6}$ The incidence of AUB accounts for $11 \%$ to $13 \%$ of the general population and increases with age to $24 \%$ between the ages of 36-40 years. ${ }^{7,8}$ Of course, the prevalence of this disease in Iran has been reported to be variable from 3.5\% to $22.9 \% .^{9}$ AUB in women can lead to complications such as feeling overwhelmed and tired and limiting women's social, occupational, and professional activities. These problems impair the quality of life of women. A decrease in the quality of life, in turn, causes mental and physical problems in women with AUB. ${ }^{10}$ Considering the relatively

Copyright $\odot 2020$ The Author(s). This is an open-access article distributed under the terms of the Creative Commons Attribution License (http:// creativecommons.org/licenses/by/4.0), which permits unrestricted use, distribution, and reproduction in any medium, provided the original work is properly cited. 
high prevalence of this disease in the population, ${ }^{11}$ it can be said that decreasing the quality of life of these patients leads to a decrease in the quality of life in the whole society. Currently, the treatments used for this disease include three classes of oral medications, intrauterine devices, and surgical procedures. Oral medications are divided into hormonal and non-hormonal groups. Common side effects of non-hormonal drugs such as NSAIDs (mefenamic acid) and anti-fibrinolytic drugs (trans-oxamic acid) are gastrointestinal problems. ${ }^{12}$ Also, hormonal drugs that cause many side effects such as weight gain, painful breasts, headaches, thrombotic events, skin problems such as acne, increased bone demineralization rate, diabetes, and menopausal complications such as vaginal dryness and hot flashes are only prescribed for short periods. ${ }^{12}$ Of course, in different countries and different cultures, complementary medicine is used to treat heavy menstrual bleeding. One of these methods is the use of homeopathy. This study aimed to evaluate the effect of homeopathy on improving AUB in women. The basis of homeopathy is the law of similarity. ${ }^{13}$ Homeopathy is the second largest medical system in the world today, recognized by the World Health Organization. ${ }^{14}$ The effects of this method on pain relief, ${ }^{15-17}$ cancer recovery, ${ }^{18}$ treatment of middle ear infection, ${ }^{19}$ chronic periodontitis, ${ }^{20}$ and treatment of $\mathrm{AUB}^{21-23}$ have been reviewed. However, researchersare still looking for more evidence in the field about the effectiveness of this method in the treatment of AUB.

\section{Objectives}

The aim of this study was to compare the efficacy of homeopathy in the treatment of abnormal bleeding, menstrual pain, and quality of life compared with placebo in patients with AUB in Tehran, Iran between September 2017 and September 2018.

\section{Methods}

This study is a double-blind clinical trial. The study population consisted of women with abnormal bleeding who referred to the Gynecology clinic of Baqiyatallah Hospital, Tehran, Iran. Subjects in this study were visited after being met all the inclusion criteria. After providing necessary explanations by the administrator, a written informed consent form was obtained from each patient.

In this study, the amount of bleeding and its duration was assessed using the PBAC score assessment chart at two times, before entering the study and after the third menstrual period. In this study, the variables of PBAC questionnaire and pain as the primary outcome, as well as GHQ quality of life score and duration of bleeding as secondary outcome were considered.

Pictorial Blood Loss Assessment Chart (PBAC) is a visual questionnaire for measuring bleeding volume. In this questionnaire, rows indicate the number of menstrual days and columns of blood-stained pads in three degrees of mild, moderate, and severe. In this questionnaire, with a sensitivity of $98 \%$ and specificity of $97 \%$, when the PBAC score is 100 or more, the menstrual bleeding volume is 80 cc or more. ${ }^{24}$

Meanwhile, the GHQ is a standard self-report questionnaire designed for all individuals in the community with 28 questions and four sub-scales. The GHQ questionnaire consists of seven questions on each scale. The four scales of this questionnaire include physical symptoms, anxiety, insomnia, social dysfunction, and depression. The questions in this questionnaire were measured on a four-point scale as "no, little, many, and too much". The minimum and maximum scores a person gets on this questionnaire are zero and 84 . A high score in this questionnaire indicates poor mental health and a low score indicates better mental health. In this questionnaire, the cut-off point 21 is determined to assess one's mental health. The reliability index of this questionnaire has been reported from $78 \%$ to $95 \%$ in various studies. ${ }^{25}$ In Iran, Palahang ${ }^{26}$ and Yaghoubi ${ }^{27}$ reported an alpha coefficient of $91 \%$ and $88 \%$, respectively.

The Visual Acuity Scale is a $10 \mathrm{~cm}$ ruler on which Smaller numbers on the left side indicate less pain and larger numbers on the right side indicate more pain in the patient. the painless word on the left end and the most severe pain word on the right end. Depending on the amount of pain, the person signs up on the continuum for the past 48 hours. In previous studies, the reliability of this questionnaire was reported from $76 \%$ to $84 \% .^{28}$

Inclusion criteria: age 35 to 55 years, confirmation of AUB (using ultrasound) by a gynecologist, no breastfeeding, normal endometrial thickness and uterine size less than 10 $\mathrm{cm}$ (in ultrasound), absence of adnexal and ovarian mass (except simple cyst less than $2 \mathrm{~cm}$ ), lack of submucosal or intramural fibroids, no subcervical fibroids greater than 3 $\mathrm{cm}$, lack of systemic, organic and hemorrhagic diseases, normal gynecological examination and Pap smear, no concurrent use of herbal remedies, hormonal and anticoagulant drugs, and other specific illnesses, including autoimmune and cancer diseases, polyps, or fibromas that require surgical intervention.

Exclusion criteria: the patient's unwillingness to participate in the study, the pregnancy at the time of the study, any intolerance to homeopathic medicines, the patient's need for other interventions as well as surgery.

After selecting the patients, they were divided into two groups with block randomization; group 1: routine treatment + homeopathic "Ipecac" treatment and group 2: routine treatment + placebo. The drugs were coded without mentioning the drug's name and conformity by the manufacturer (Dr. Reckeweg's German company) and participants were asked to use the same instructions. In this study, two groups were asked to use a routine homeopathic medication, one of the homeopathic remedies, "Ipecac", which according to the principles of making homeopathic medicines made with potency 30 , used a sublingual on the first visit. The same dose is repeated in case the bleeding persists after 24 hours. In the placebo group according to the same procedure, the placebo was evaluated. Patients 
were also asked to record and report to the investigator if they observed any adverse drug reactions.

In this study, descriptive statistics (mean, standard deviation, frequency, and ratio) and inferential statistics (chi-square test, independent $t$ test, Mann-Whitney test, dependent t-test, Wilcoxon test) were used to determine whether or not the response variable was normal. Kolmogorov-Smirnov test has been done. SPSS software version 21 and a significant level of $5 \%$ were considered as significant level. To estimate sample size in this study, taking into account $\alpha=0.05, \beta=0.1$ and $d=1$ according to experts' opinion, and using the following formula, 50 samples were calculated.

$n=2\left(Z_{\frac{\alpha}{2}}+Z_{\beta}\right)^{2} / d^{2}$

\section{Results}

In this study, 50 patients were enrolled of which 46 remained at the end of the study (Figure 1). The demographic characteristics of the study participants in the two groups are presented in Table 1. Based on the information in this table, we can be assured of the same age and education distribution between the two study groups. Mean and standard deviation of the number of days of bleeding, PBAC score, pain score, physical symptoms questionnaire, anxiety and insomnia, social dysfunction, depression, and mental health scores were shown at baseline. Based on the information in this table, we can be certain that the two groups are identical in the mentioned variables. Table 2 shows the mean and standard deviation of the variables studied at baseline and after three months of intervention in the two groups. Based on the results reported in this table, it can be said that despite the relative improvement in PBAC score, the number of bleeding days, and depression score in the homeopathic treatment group, this improvement was not statistically significant in the two groups. The homeopathic treatment group showed more improvement in pain score, physical symptoms, anxiety, insomnia, social dysfunction, and mental health compared to the control group.

\section{Discussion}

Menstrual disorders are major health problems for many women. ${ }^{29,30}$ It should be noted that AUB is responsible for about two-third of cases of hysterectomy in women, which increases the surgical complications, the risk of morbidity and mortality and imposes a high cost on the national health system. ${ }^{8,30}$ Since the use of complementary medicine has been shown to have a significant effect on the treatment of diseases and pain relief,, ${ }^{31,32}$ this study aimed to investigate the effect of homeopathic "Ipecac" on the improvement of AUB in women. The results of this study showed that despite a slight improvement in PBAC score, bleeding day, and depression score in the homeopathic

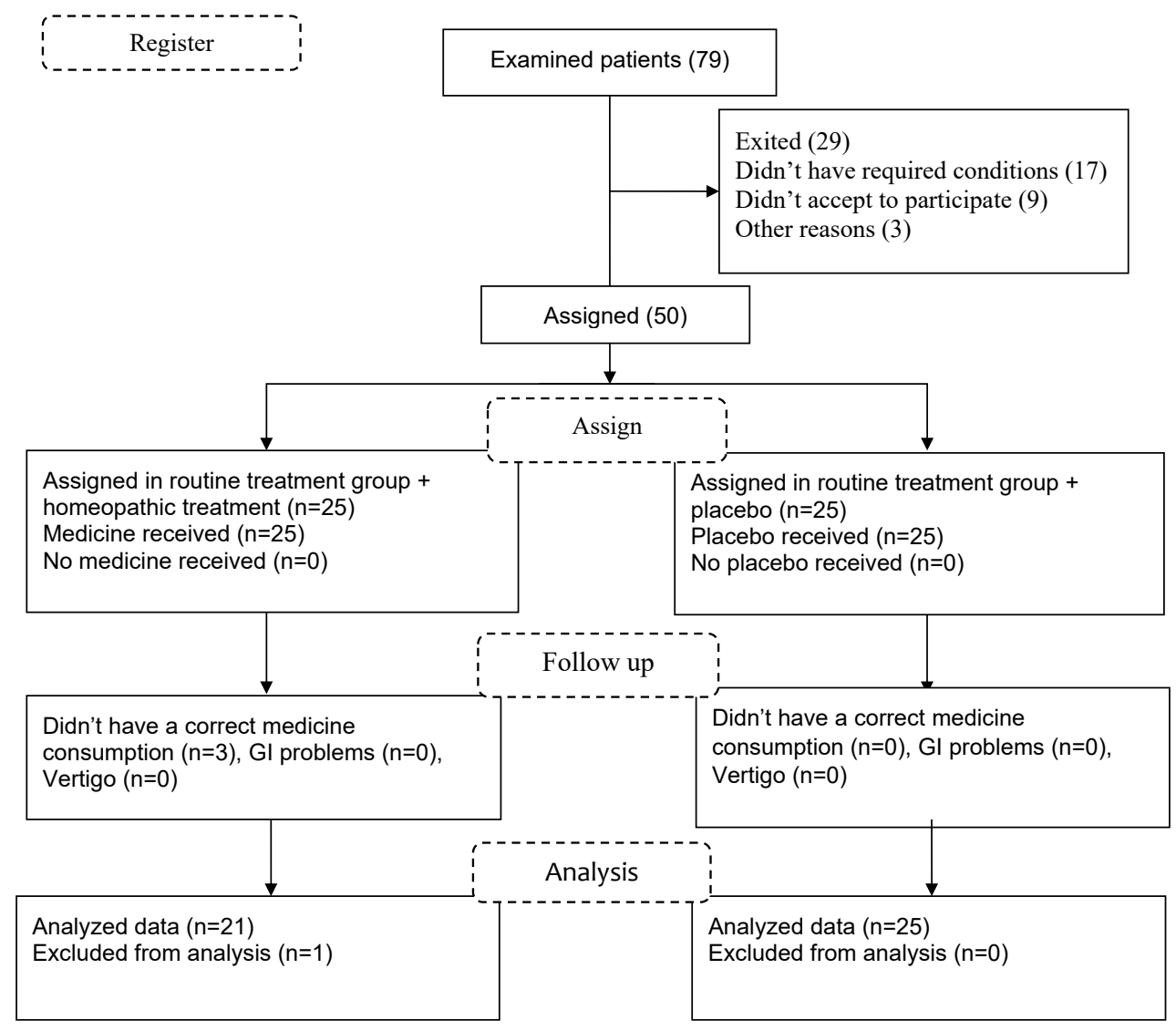

Figure 1. Follow up Study. 
Table 1. Distribution Frequency Sex, Age, and Basic Variables in the Two Groups

\begin{tabular}{|c|c|c|c|c|c|c|}
\hline & & \multicolumn{2}{|c|}{ Routine Treatment + Placebo } & \multicolumn{2}{|c|}{ Routine Treatment + Homeopathic Medicine } & \multirow{2}{*}{ P Value } \\
\hline & & No & $\%$ & No & $\%$ & \\
\hline Sex & Woman & 25 & 38 & 21 & 30 & 0.47 \\
\hline \multirow{4}{*}{ Education } & $<$ Diploma & 9 & 34.6 & 2 & 9.5 & \multirow{4}{*}{0.20} \\
\hline & Diploma & 4 & 15.4 & 6 & 28.6 & \\
\hline & B.S. & 10 & 42.3 & 10 & 47.6 & \\
\hline & M.S. \& PhD & 2 & 7.7 & 3 & 14.3 & \\
\hline \multirow{3}{*}{ Age } & $<30$ & 4 & 15.4 & 2 & 9.5 & \multirow{3}{*}{0.30} \\
\hline & $31-40$ & 4 & 15.4 & 4 & 19.0 & \\
\hline & $>41$ & 17 & 69.2 & 15 & 71.4 & \\
\hline \multicolumn{2}{|l|}{ Quantitative variables } & Mean & SD & Mean & SD & \\
\hline \multicolumn{2}{|l|}{ Number of bleeding days } & 13.58 & 8.24 & 12.90 & 7.24 & 0.77 \\
\hline \multicolumn{2}{|l|}{ PBAC scale } & 340.27 & 243.32 & 312.33 & 218.96 & 0.68 \\
\hline \multicolumn{2}{|l|}{ VAS } & 3.42 & 2.70 & 5.05 & 3.32 & 0.07 \\
\hline \multicolumn{2}{|l|}{ Physical symptoms } & 11.42 & 4.23 & 9.38 & 3.79 & 0.09 \\
\hline \multicolumn{2}{|l|}{ Anxiety and insomnia } & 11.88 & 5.13 & 11.14 & 4.34 & 0.60 \\
\hline \multicolumn{2}{|l|}{ Social dysfunction } & 12.23 & 2.53 & 11.71 & 2.85 & 0.51 \\
\hline \multicolumn{2}{|l|}{ Depression } & 16.62 & 5.15 & 18.76 & 2.59 & 0.09 \\
\hline \multicolumn{2}{|l|}{ Mental health scale } & 52.15 & 13.33 & 51.00 & 9.90 & 0.74 \\
\hline
\end{tabular}

$P$ value was calculated based on the chi-square test, Mann-Whitney, and independent $t$ test.

Table 2. Mean and SD of Study Variables at the Beginning and After 3 Months After Intervention in the Two Groups

\begin{tabular}{|c|c|c|c|c|c|c|c|c|}
\hline & & \multicolumn{2}{|c|}{ Beginning of Study } & \multicolumn{2}{|c|}{ After 3 Months } & \multirow{2}{*}{ Effectiveness } & \multirow{2}{*}{$P$ Value $^{*}$} & \multirow{2}{*}{$P$ Value $^{* *}$} \\
\hline & & Mean & SD & Mean & SD & & & \\
\hline \multirow{2}{*}{$\begin{array}{l}\text { Number of } \\
\text { bleeding days }\end{array}$} & Routine treatment + Placebo & 13.6 & 8.2 & 9.9 & 5.6 & 0.53 & 0.019 & \multirow{2}{*}{0.815} \\
\hline & Routine treatment + Homeopathic medicine & 12.9 & 7.2 & 8.7 & 3.3 & 0.75 & 0.011 & \\
\hline \multirow{2}{*}{ PBAC scale } & Routine treatment + Placebo & 340.3 & 243.3 & 191.3 & 178.3 & 0.70 & 0.011 & \multirow{2}{*}{0.244} \\
\hline & Routine treatment + Homeopathic medicine & 312.3 & 219.0 & 79.1 & 50.8 & 1.47 & 0.000 & \\
\hline \multirow{2}{*}{ VAS } & Routine treatment + Placebo & 3.4 & 2.7 & 2.4 & 2.6 & 0.39 & 0.043 & \multirow{2}{*}{0.001} \\
\hline & Routine treatment + Homeopathic medicine & 5.1 & 3.3 & 1.3 & 1.2 & 1.51 & $<0.001$ & \\
\hline \multirow{2}{*}{$\begin{array}{l}\text { Physical } \\
\text { symptoms }\end{array}$} & Routine treatment + Placebo & 11.4 & 4.2 & 13.0 & 3.3 & 0.42 & 0.037 & \multirow{2}{*}{$<0.001$} \\
\hline & Routine treatment + Homeopathic medicine & 9.4 & 3.8 & 16.5 & 2.0 & 2.35 & $<0.001$ & \\
\hline \multirow{2}{*}{$\begin{array}{l}\text { Anxiety and } \\
\text { insomnia }\end{array}$} & Routine treatment + Placebo & 11.9 & 5.1 & 14.4 & 3.8 & 0.55 & 0.004 & \multirow{2}{*}{0.006} \\
\hline & Routine treatment + Homeopathic medicine & 11.1 & 4.3 & 17.1 & 3.5 & 1.53 & $<0.001$ & \\
\hline \multirow{2}{*}{ Social dysfunction } & Routine treatment + Placebo & 12.2 & 2.5 & 12.5 & 2.9 & 0.09 & 0.689 & \multirow{2}{*}{0.008} \\
\hline & Routine treatment + Homeopathic medicine & 11.7 & 2.9 & 14.5 & 2.6 & 1.02 & 0.001 & \\
\hline \multirow{2}{*}{ Depression } & Routine treatment + Placebo & 16.6 & 5.2 & 16.9 & 5.6 & 0.06 & 0.707 & \multirow{2}{*}{0.395} \\
\hline & Routine treatment + Homeopathic medicine & 18.8 & 2.6 & 19.9 & 2.8 & 0.42 & 0.010 & \\
\hline \multirow{2}{*}{$\begin{array}{l}\text { Mental health } \\
\text { scale }\end{array}$} & Routine treatment + Placebo & 52.2 & 13.3 & 9.9 & 5.6 & 4.14 & 0.027 & \multirow{2}{*}{$<0.001$} \\
\hline & Routine treatment + Homeopathic medicine & 51.0 & 9.9 & 8.7 & 3.3 & 5.73 & $<0.001$ & \\
\hline
\end{tabular}

$P$ value was calculated based on independent $t$ test, dependent $t$ test, Mann-Whitney, and Wilcoxon tests.

* $P$ value1: within-group comparison.

** $P$ value2: between groups comparison.

treatment group, the improvement was not statistically significant in the two groups. In this respect, the results of this study were consistent with the study by Das et $\mathrm{al}^{33}$ and inconsistent with the studies by Ammerman et al ${ }^{22}$ and El-Nashar et al..$^{24}$ Denisova et al. ${ }^{34}$ The results of this study, similar to studies by Mahmoudian and Sadri ${ }^{15}$ Teixeira et al. ${ }^{16}$ Barkey et $\mathrm{al}^{17}$ Kundu et $\mathrm{a}^{35}$ showed a significant improvement in homeopathy compared to routine treatment and inconsistent with the study by Koley et $\mathrm{a}^{36}$ The reason for this effect can be justified in the fact that in homeopathy the physician's diagnostic and therapeutic approach is based on detecting a disorder in the mental, 
nervous, glandular, and immune systems that causes symptoms in various organs of the body. The purpose of drug administration in homeopathy is to stimulate these systems. ${ }^{37}$ Therefore, the effect of homeopathic treatment on pain control can be considered as stimulation of the nervous system.

The vital point about using homeopathic remedies is that they are considered to be non-chemical because of their source of plants, animal, mineral, nosode, and sarcode; therefore, there are fewer reported cases that have side effects. Another reason for the lesser side effects of homeopathic remedies is their use in the dilution process. In this method, by diluting and shaking the drug molecules, the supramolecular clusters are formed and the drug molecules are converted into three-dimensional cavities that are exactly complementary to the pathogenic molecules. ${ }^{38}$ The two factors, 1-non-chemical and 2-thinning have reduced the side effects of homeopathic medicines thus this treatment is more popular. Therefore, one of the reasons for improving the quality of life of patients using homeopathy is the two factors mentioned.

Finally, the strengths of this study are the appropriate sample size, robust design (double-blind randomized clinical trial), and homogeneity of participants in this study.

Meanwhile, limitations of this study were the discussion of follow-up of patients during menstruation and drug use. Repeated and frequent researcher contact with patients was sometimes difficult and these follow-ups were sometimes very unpleasant for patients and their families.

\section{Conclusion}

Considering the efficacy of homeopathic "Ipecac" in reducing pain, enhancing the quality of life of women with high bleeding in this study, and lower side effects in this treatment, it can be suggested to reduce AUB in women.

\section{Authors' Contributions}

$\mathrm{ZN}$ : Writing the proposal and final report and article, Data entry; ZD: Collecting data; AK: Scientific advice on homeopathy; RH: Patient referral, Scientific advice in the field of obstetrics and gynecology; MA: Patient referral; AT: Scientific advice in the field of psychiatry and quality of life and MSI: Data analysis, scientific advice on the proposal, final report and article.

\section{Conflict of Interest Disclosures}

The authors declare that they have no conflicts of interest.

\section{Ethical Approval}

This study was approved by the Medical Ethics Committee of Baqiyatallah University of Medical Sciences on $01 / 24 / 2017$ by IR.Bmsu.REC.1395.220, and also in the Iranian Clinical Trial Registration Center on 03/05/2018. Code IRCT20170118032033N3 has been registered and approved.
Research Highlights

\section{What Is Already Known?}

AUB is a major health problem for many women. Oral medications, intrauterine devices, and surgical procedures are used to treat this condition.

\section{What This Study Adds?}

This study showed that homeopathy can be effective in reducing pain and improving the quality of life of women with abnormal uterine bleeding. Also, this method of treatment can be recommended because the side effects of these drugs are far less than modern medicine drugs and have a more reasonable cost.

\section{Acknowledgments}

Thanks to financial support, guidance, and advice from the "Clinical Research Development Unit of Baqiyatallah Hospital”.

\section{References}

1. Matteson KA, Boardman LA, Munro MG, Clark MA. Abnormal uterine bleeding: a review of patient-based outcome measures. Fertil Steril. 2009;92(1):205-216. doi:10.1016/j. fertnstert.2008.04.023.

2. van Dongen $\mathrm{H}$, de Kroon CD, Jacobi CE, Trimbos JB, Jansen FW. Diagnostic hysteroscopy in abnormal uterine bleeding: a systematic review and meta-analysis. BJOG. 2007;114(6):664675. doi:10.1111/j.1471-0528.2007.01326.x.

3. Côté I, Jacobs P, Cumming DC. Use of health services associated with increased menstrual loss in the United States. Am J Obstet Gynecol.2003;188(2):343-348.doi:10.1067/mob.2003.92.

4. Liu Z, Doan QV, Blumenthal P, Dubois RW. A systematic review evaluating health-related quality of life, work impairment, and health-care costs and utilization in abnormal uterine bleeding. Value Health. 2007;10(3):183-194. doi:10.1111/j.15244733.2007.00168.x.

5. Critchley HO, Maybin JA. Molecular and cellular causes of abnormal uterine bleeding of endometrial origin. Semin Reprod Med. 2011;29(5):400-409. doi:10.1055/s-0031-1287664.

6. Hurskainen R, Grenman S, Komi I, et al. Diagnosis and treatment of menorrhagia. Acta Obstet Gynecol Scand. 2007; 86(6):749-757. doi:10.1080/00016340701415400.

7. Livingstone $M$, Fraser IS. Mechanisms of abnormal uterine bleeding. Hum Reprod Update. 2002;8(1):60-67. doi:10.1093/ humupd/8.1.60

8. Marret H, Fauconnier A, Chabbert-Buffet $\mathrm{N}$, et al. Clinical practice guidelines on menorrhagia: management of abnormal uterine bleeding before menopause. Eur J Obstet Gynecol Reprod Biol. 2010;152(2):133-137. doi:10.1016/j. ejogrb.2010.07.016.

9. Tabarrai M, Qaraaty M, Eftekhar T, et al. Etiologies of hyper menorrhea (The view points of Traditional Iranian Medicine). Journal of Islamic and Iranian Traditional Medicine. 2013;4(1):25-34. [Persian].

10. Vitale SG, Ferrero S, Ciebiera M, et al. Hysteroscopic endometrial resection vs. hysterectomy for abnormal uterine bleeding: impact on quality of life and sexuality. Evidence from a systematic review of randomized controlled trials. Curr Opin Obstet Gynecol. 2020;32(2):159-165. doi:10.1097/ gco.0000000000000609.

11. Karlsson TS, Marions LB, Edlund MG. Heavy menstrual bleeding 
significantly affects quality of life. Acta Obstet Gynecol Scand. 2014;93(1):52-57.doi:10.1111/aogs.12292.

12. Tansaz M, Memarzadehzavareh H, Qaraaty M, Eftekhar T, Tabarrai M, Kamalinejad M. Menorrhagia management in Iranian traditional medicine.J Evid Based Complementary Altern Med. 2016;21(1):71-76. doi:10.1177/2156587215589522.

13. Chopra P, Chopra P. Homeopathy in dentistry-an overview. Int J Contemp Dent. 2011;2(2):105.

14. Darby P. How homeopathy can be used in dental practice. Dental Nursing. 2011;7(11):634-637. doi:10.12968/ denn.2011.7.11.634.

15. Mahmoudian A, Sadri G. Homeopathy satisfaction in Iran. Iran J Nurs Midwifery Res. 2014;19(5):496-502.

16. Teixeira MZ, Podgaec S, Baracat EC. Potentized estrogen in homeopathic treatment of endometriosis-associated pelvic pain: a 24-week, randomized, double-blind, placebo-controlled study. Eur J Obstet Gynecol Reprod Biol. 2017;211:48-55. doi:10.1016/j.ejogrb.2017.01.052.

17. Barkey E, Kaszkin-Bettag M. A homeopathic Arnica patch for the relief of cellulitis-derived pain and numbness in the hand. Glob Adv Health Med. 2012;1(2):18-20. doi:10.7453/ gahmj.2012.1.2.005.

18. Frass $\mathrm{M}$, Friehs $\mathrm{H}$, Thallinger $\mathrm{C}$, et al. Influence of adjunctive classical homeopathy on global health status and subjective wellbeing in cancer patients - a pragmatic randomized controlled trial. Complement Ther Med. 2015;23(3):309-317. doi:10.1016/j.ctim.2015.03.004.

19. Fixsen A. Should homeopathy be considered as part of a treatment strategy for otitis media with effusion in children? Homeopathy. 2013;102(2):145-150.doi:10.1016/j.homp.2013.01.004.

20. Mourão LC, Cataldo DM, Moutinho H, Fischer RG, Canabarro A. Additional effects of homeopathy on chronic periodontitis: a 1-year follow-up randomized clinical trial. Complement Ther Clin Pract. 2014;20(3):141-146. doi:10.1016/j. ctcp.2014.03.003.

21. Karimi-Zarchi M, Dehghani-Firoozabadi R, Tabatabaie A, et al. A comparison of the effect of levonorgestrel IUD with oral medroxyprogesterone acetate on abnormal uterine bleeding with simple endometrial hyperplasia and fertility preservation. Clin Exp Obstet Gynecol. 2013;40(3):421-424.

22. Ammerman SR, Nelson AL. A new progestogen-only medical therapy for outpatient management of acute, abnormal uterine bleeding: a pilot study. Am J Obstet Gynecol. 2013;208(6):499. e491-495. doi:10.1016/j.ajog.2013.02.013.

23. Oberbaum M, Galoyan N, Lerner-Geva L, et al. The effect of the homeopathic remedies Arnica montana and Bellis perennis on mild postpartum bleeding--a randomized, double-blind, placebo-controlled study--preliminary results. Complement Ther Med. 2005;13(2):87-90. doi:10.1016/j.ctim.2005.03.006.

24. El-Nashar SA, Shazly SAM, Famuyide AO. Pictorial blood loss assessment chart for quantification of menstrual blood loss: a systematic review. Gynecol Surg. 2015;12(3):157-163. doi:10.1007/s10397-015-0893-5.
25. Golderberg D, Williams P. A User's Guide to the General Health Questionnaire. Windsor, UK: NFER-Nelson; 1988.

26. Palahang $H$, Nasr M, Brahani MN, Shahmohammadi D. Epidemiology of mental illnesses in Kashan city. Iranian Journal of Psychiatry and Clinical Psychology. 1996;2(4):1927. [Persian].

27. Yaghoubi N. The Study of Social Epidemic Disorder in Rural and Urban of Somesaraye Gilan [thesis]. Tehran: Iran University of Medical Sciences; 2009. [Persian].

28. Boonstra AM, Schiphorst Preuper HR, Reneman MF, Posthumus JB, Stewart RE. Reliability and validity of the visual analogue scale for disability in patients with chronic musculoskeletal pain. Int J Rehabil Res. 2008;31(2):165-169. doi:10.1097/ MRR.0b013e3282fc0f93.

29. Duckitt K. Managing perimenopausal menorrhagia. Maturitas. 2010;66(3):251-256. doi:10.1016/j.maturitas.2010.03.013.

30. Protheroe J. Modern management of menorrhagia. J Fam Plann Reprod Health Care. 2004;30(2):118-122. doi:10.1783/147118904322995537.

31. Bao Y, Kong X, Yang L, et al. Complementary and alternative medicine for cancer pain: an overview of systematic reviews. Evid Based Complement Alternat Med. 2014;2014:170396. doi:10.1155/2014/170396.

32. Barlow T, Downham C, Barlow D. The effect of complementary therapies on post-operative pain control in ambulatory knee surgery: a systematic review. Complement Ther Med. 2013; 21(5):529-534. doi:10.1016/j.ctim.2013.06.008.

33. Das KD, Ghosh S, Das AK, et al. Treatment of hemorrhoids with individualized homeopathy: an open observational pilot study. J Intercult Ethnopharmacol. 2016;5(4):335-342. doi:10.5455/ jice. 20160608030224.

34. Denisova TG, Gerasimova LI, Pakhmutova NL, Mahesh S, Vithoulkas G. Individualized homeopathic therapy in a case of obesity, dysfunctional uterine bleeding, and autonomic dystonia. Am J Case Rep. 2018;19:1474-1479. doi:10.12659/ ajcr.913328.

35. Kundu T, Ghosh K, Shaikh A, et al. [Homeopathic medicine reduces pain and hemarthrosis in moderate and severe hemophilia: a multicentric study]. Complement Med Res. 2018;25(5):306-312. doi:10.1159/000486557.

36. Koley M, Saha S, Ghosh S. A double-blind randomized placebo-controlled feasibility study evaluating individualized homeopathy in managing pain of knee osteoarthritis. J Evid Based Complementary Altern Med. 2015;20(3):186-191. doi:10.1177/2156587214568668.

37. World Health Organization (WHO). Legal Status of Traditional Medicine and Complementary. Geneva: WHO; 2001.

38. Ahrari Y, Shahabian M. A Review of the Molecular Mechanisms and Biochemical Evaluation of Homeopathy Treatment. International Congress of Complementary and Alternative Medicine. Mashhad: Mashhad General Practitioners Association; 2016. 